\title{
EFFECT OF DIODE LASER COMBINED WITH HYALURONIC ACID GEL IN TREATMENT OF RECURRENT APHTHOUS STOMATITIS IN CHILDREN: RANDOMIZED CLINICAL TRIAL
}

\author{
Hany Kamel Mohamed Shalaby * and Shaimaa Mohamed Mahfouz**
}

\begin{abstract}
Background: Recurrent Aphthous Stomatitis (RAS) is a painful rounded ulcer characteristic by erythematous margin and pseudo yellowish- gray membrane in its center .All forms of RAS have bad effects on quality of life that interfere with daily activities. Hyaluronic acid has essential part in tissue hydrodynamics, cell migration, proliferation and differentiation. It shows an antiinflammatory role so; it prevents tissue destruction and helps in tissue healing. Low level laser therapy is recognized with various terminologies such as "biostimulator," and "cold laser," It has role in the management of RAS, it has a wide spectrum of clinical applications which include herpes labialis, angular cheilitis, trismus, paresthesia, dentin hypersensitivity, temporomandibular joint pain, and in the postoperative phase.
\end{abstract}

Materials and Method: Forty five normal healthy males and females children aged from (4-10 years) suffering from aphthous lesions were used in this study. Children were examined in Outpatient clinic pediatric Dentistry Department, Faculty of Dentistry, Suez canal University by a clinician. Each patient had one minor RAS of less than $72 \mathrm{~h}$ duration or two nearby minor aphthous lesions of less than $72 \mathrm{~h}$ at the same side of oral cavity. Patients were evenly divided into three groups (15 patients in each) with the method of simple randomization, Patients of group I were treated with topical application of hyaluronic acid gel, those of group II were treated with diode laser and group III patients were treated with diode laser followed by topical application of hyaluronic acid gel. The patients were evaluated at $\left(0,2^{\text {nd }}, 4^{\text {th }}\right.$ and $\left.6^{\text {th }}\right)$ days, for measuring ulcer size and pain score.

Results: At the $2^{\text {nd }}, 4^{\text {th }}$ and $6^{\text {th }}$ days there was statistical significance decrease in mean size of the ulcer of group III when compared to both groups (I) and (II) . On other hands, at days 2 and 6 there was statistical significance decrease in mean of pain score in group III when compared to group I. There was also statistical significance decrease in mean of pain score in group II when compared to group I at the $4^{\text {th }}$ day of evaluation.

Conclusion: Hyaluronic acid gel combined with diode laser are effective in treatment of RAS.

Key words: Diode laser ; hyaluronic acid; aphthous ulcer; Children

*Associate Professor of Oral Medicine and Periodontology, Faculty of Dentistry, Suez Canal University.

** Lecturer of Pedodontics, Preventive Dentistry and Dental Public Health, Faculty of Dentistry, Suez Canal University. 


\section{INTRODUCTION}

Recurrent aphthous stomatitis (RAS) is the most common disease of mucous membrane, It affects $5-25 \%$ of general population ${ }^{(1,2)}$. It is more frequent in patient between $10-40$ years of age ${ }^{(1,3)}$. There are three types of RAS; minor $\leq 5 \mathrm{~mm}$, major $\geq 5 \mathrm{~mm}$, and herpetiform which present as multiple small clusters of pinpoint lesions ${ }^{(4)}$. $70 \%$ to $87 \%$ of all RAS cases are minor type ${ }^{(5)}$. It has different sizes and shapes. There are many causative factors that are responsible for frequent oral ulcerations such as local genetic factors, nutritional deficiencies, trauma, viral, bacterial infections and immune or endocrine disturbances ${ }^{(6)}$.

Diagnosis of RAS is performed by history \& clinical examination, exclusion of other causes of ulcerative stomatitis as systemic diseases, viral infection, trauma from dental appliances, the site of occurrence and other general manifestation that can be associated with other type of ulceration in oral cavity, should be explored before its diagnosis, RAS accounts for $25 \%$ of recurrent ulcers in adults and $40 \%$ in children $^{(7)}$. The main factor in the identification of RAS is the history of recurrent ulcers which are induced in systematic periods and are usually self-limiting ${ }^{(8)}$.The use of many treatment modalities in management of aphthous stomatitis as topical and systemic steroids, Dapson, Talidomid, Tetracycline, Colchicine etc, showed side effects so there is no absolute management for aphthous ulcers. All the treatments aim to decrease healing time, pain, size and number of the ulcers, and to increase time of ulcer-free ${ }^{(9)}$.

Hyaluronic acid (HA) is a high molecular weight polysaccharide (glycosaminoglycan). It is known also as hyaluronan or hyaluronate .It is present in numerous living tissues and is considered as a main a major component of extracellular matrix ${ }^{[10,11]}$. It has an important role in the function of both extracellular mineralized and non-mineralized matrices. It has essential part in tissue hydrodynamics, cell migration, proliferation and differentiation ${ }^{(10,12)}$. HA has an anti-inflammatory role so, it prevents tissue break down and helps in tissue healing ${ }^{(10,13)}$. In addition, exogenous HA has numerous uses in the treatment of inflammatory processes in different medical fields such as dermatology, ophthalmology and orthopedics ${ }^{(10,11)}$.

HA has used as treatment agent for chronic osteoarthritis and in aesthetic surgery as well as for tissue engineering applications ${ }^{(14)}$. Moreover, the anti-inflammatory effect of HA applied for treatment of periodontitis ${ }^{(15)}$. In vitro study has induced reduction of periodontal pathogens including Aggregatibacter actinomycetemcomitans and Porphyromonas gingivalis after application of (HA) topically ${ }^{(16) .}$

Laser is a unique form of energy which is widely used in medicine and dentistry due to its reparative, analgesic, and anti-inflammatory benefits. Different types of laser such as Diode, CO2, and Nd:YAG are used for treatment of complications on soft and hard tissues ${ }^{(17)}$. Randomized clinical trial ${ }^{(18)}$ on ulcer healing, has revealed that low level laser therapy such as diode laser has many advantageous in the treatment of oral aphthous lesions by decreasing the period of wound healing and pain reduction without any side effects. However, the effect of hyaluronic acid gel combined with diode laser has not been searched extensively, therefore, this trial aims to evaluate and compare the effect of hyaluronic acid gel, diode laser, and diode laser combined with hyaluronic acid gel on the treatment of RAS on children.

The null hypothesis was that there is no difference in the effect of diode laser, hyaluronic acid gel, and diode laser with hyaluronic acid gel on treatment of RAS in children.

\section{Aim of the Study}

This study was conducted to evaluate and compare the effect of hyaluronic acid gel, diode laser, 
and diode laser combined with hyaluronic acid gel on the treatment of RAS in children.

\section{MATERIALS AND METHODS}

This study was designed as a randomized clinical trial to evaluate the effect of low level laser (diode laser)*, hyaluronic acid gel ${ }^{* *} 0.2 \%$ and diode laser combined with hyaluronic acid gel on treatment of RAS in children and comparing their effects. The parents signed a consent form and were informed about the nature of the procedure before starting. Forty five normal healthy males and females children aged from (4-10) years with average age $4 \pm 6.8$ suffering from aphthous lesion were used in this study. Children were examined in Outpatient clinic pediatric Dentistry Department, Faculty of Dentistry, Suez canal University by a clinician and the diagnosis was confirmed through patient history and clinical examination. Each patient had one minor RAS of less than $72 \mathrm{~h}$ duration or two nearby minor aphthous lesions of less than $72 \mathrm{~h}$ at the same side of oral cavity (the size of the two lesions plus the distance between them was not more than $9 \mathrm{~mm}$ ). The diagnosis of RAS was based on clinical examination

\section{Inclusion criteria}

1- Children should be willing to participate in the study.

2- Children should have a history of RAS for at least two years with a frequency of at least one outbreak every two months

3- Each ulcer had well defined margin for a period less than two days in Child complained from pain.

4- Each ulcer was in applicable area for easy management.

\footnotetext{
* Lasotronix, Poland.

** Gengigel,Ricer Farma, Biotech Egypt.
}

\section{Exclusion criteria}

1- Patients had history of using topical or systemic medication for mangement RAS, such as corticosteroid therapy, antibiotics or analgesics during the previous month.

2- Patient with special syndrome \& immunological disease where RAS is one of its clinical presentation.

3- Patient with allergic conditions.

During the enrolment visit, a code number was given for each patients, and computer generated table were used with 45 numbers randomly distributed into three blocks to allocate them to one of the three therapeutic groups. Patients were evenly divided into three groups (15 patients in each), Patients of group I were treated with topical application of hyaluronic acid gel $0.2 \%$ (Fig.1), those of group II were treated with diode laser and group III patients were treated with diode laser followed by topical application of hyaluronic acid gel. Four of the patients did not complete the procedure (Three from group I and one from group II) and were excluded from the study. Each patient subjected to complete clinical examination using examination chart that explained all details for each child including personal data, medical and dental history as well as history of the ulcer. No topical or injectable anesthesia was applied before the procedure in the three groups.

Patients in group I and III were instructed to apply gel twice daily (after lunch and immediately before sleepin) ${ }^{(19)}$, Gel application was maintained for one week and each child should not eat or drink for half an hour after gel application in both groups.

All patients in group II and group III received a single session of laser treatment. Ulcers were ablated with diode laser (Fig.2). A diode lasers was used 

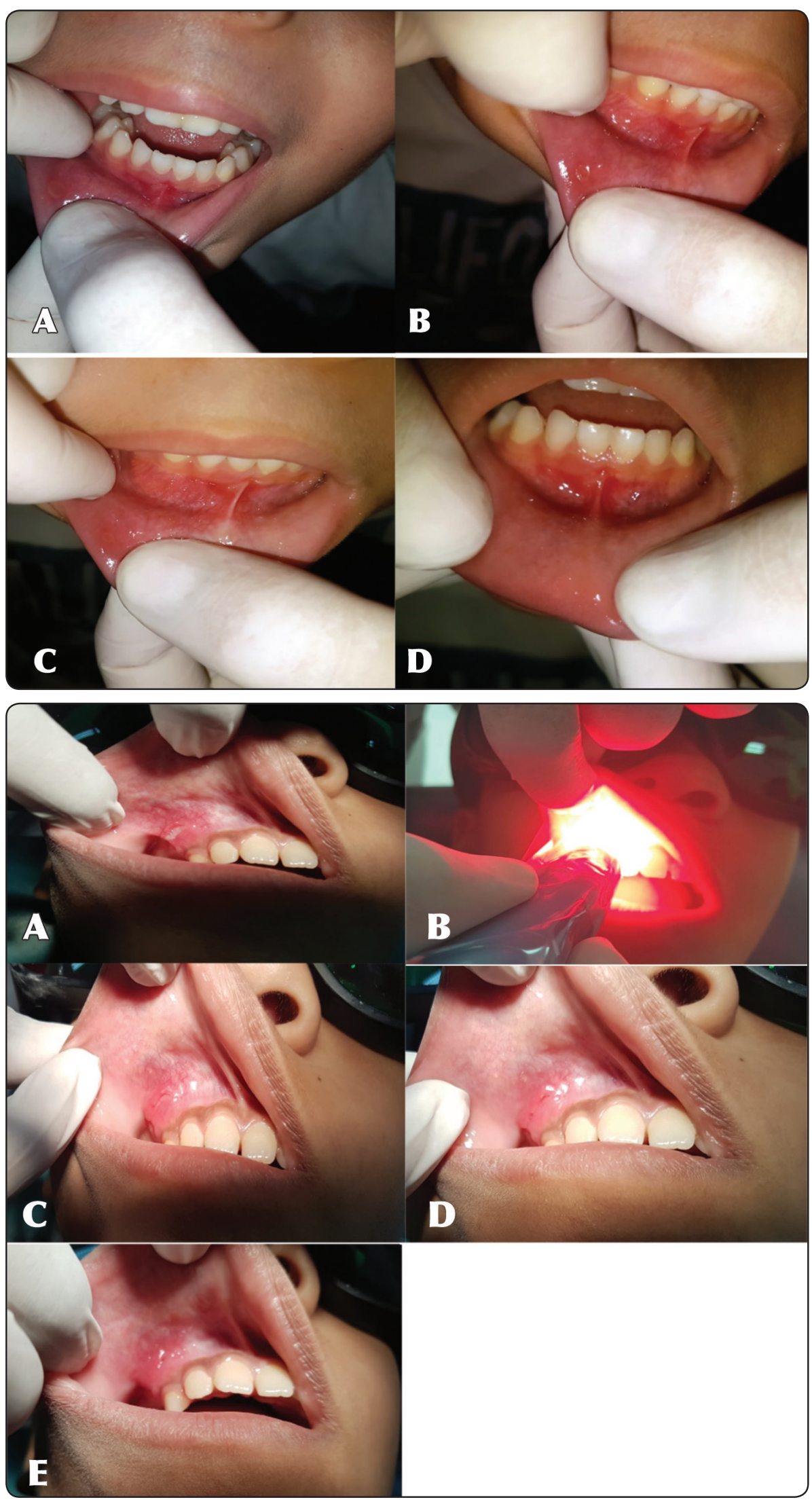

Fig. 1: Management of RAS with hyaluronic acid gel (group I): (a) preoperative view of RAS. (b)RAS ulcer after 2 days (c) RAS ulcer after 4 days (d)RAS ulcer in child after 6 days

Fig. 2: Management of RAS with diode laser (group II): (a) pre-opertive view of RAS. (b) Laser application on RAS ulcer (c) RAS ulcer after 2 days (d) RAS ulcer after 4 days. (e) RAS ulcer after 6 day. 
for the treatment of RAS in a non-contact mode. Diode laser was started at a de-focused mode from the lesion $(5-8 \mathrm{~mm})$ and advanced slowly towards the area ending up 2-3mm away and continuous wave from the outer border of the lesion to the inner "painting "the all area. The setting was put at $0.4 \mathrm{~J} / \mathrm{cm} 2$ for 20 seconds with a refractory period of 15-20 seconds between laser "passes" to allow for tissue relaxation ${ }^{(18)}$.

In group III, ulcers were ablated with diode laser with the same power setting in group (II) then patient were rinsing their mouth with tap water before topical application of hyaluronic acid gel.

\section{Evaluation of patients}

Patients were asked to get appointment in pedodontic outpatient clinic on the morning (10 am) at (0, 2, 4 and 6) days after treatment, for detection and measurement of ulcer size and pain score in each period of evaluation. Parents were advised not to use any other topical or systemic medication for the treatment of aphthous ulcers during allocation in current study. In addition, all parents were asked to record any discomfort during evaluation periods.

\section{Methods of evaluations}

\section{1-Pain severity}

Non- contact pain was evaluated with (WongBaker faces rating Scale) ${ }^{(20)}$ from 1-6, (Fig. 3) and children were educated to select the face which simulates their level of pain perception. WongBaker were recorded (0) baseline, 2, 4 and 6 days after treatment for each patient. Non-contact pain means the spontaneous pain which is felt without any stimulation of the ulcer. The children's condition was recorded by another investigator

Any pain associated with speaking, chewing and brushing were recorded by parents additionally, the day of pain disappearance.

\section{2-Sizes of the ulcers}

Assessed on days 0, 2,4 and 6 days after treatment by using digital caliper. Ulcer size was measured; the space between two opposed outer edges of the white margin was determinated by using two dimensions nearly perpendicular to each other then multiplied to obtain cross-sectional area of the ulcer.

\section{RESULTS}

The study was performed on 45 male and female children with average age $4 \pm 6.8$ years, the study conducted to evaluate and compare the effect of diode laser, hyaluronic acid, and diode laser combined with hyaluronic acid on treatment of RAS on children. The mean age, lesion size and pain perception of the three treated groups were nearly the same at the beginning of the study. There

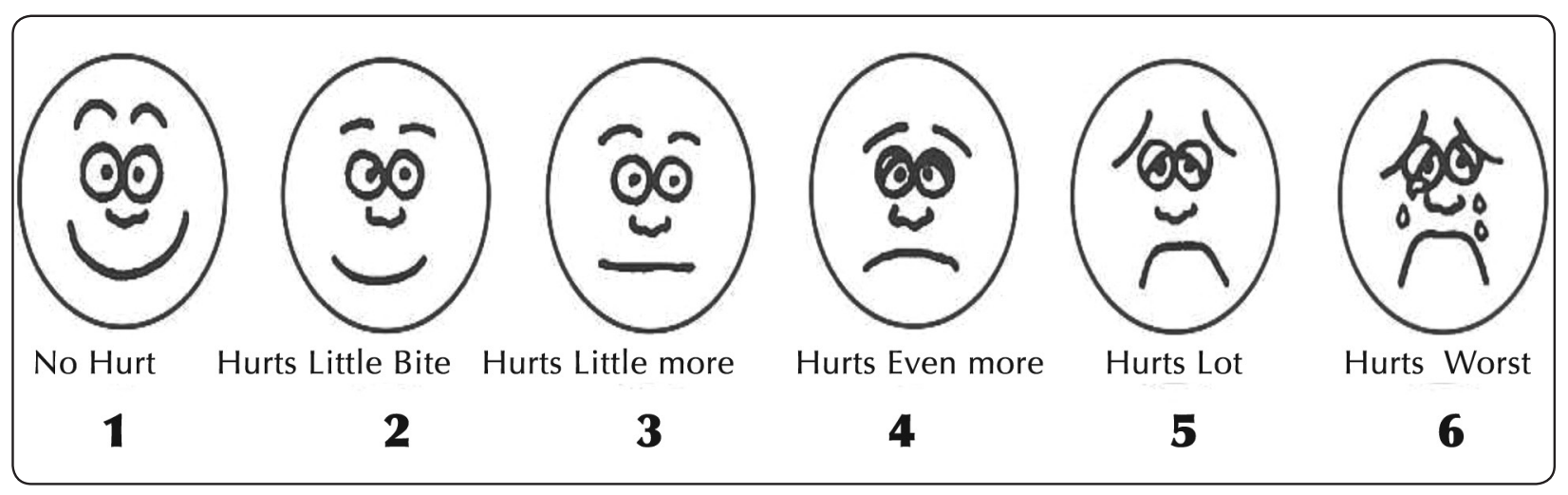

Fig. 3: Wong-Baker FACES Pain Rating Scale (20) 
were no side effects in all treated groups during all evaluation periods.

\section{Ulcer size:}

The results of this study recorded that, at day (0) there was non-statistical significance difference in mean size of the ulcer between the three treated groups; it was $7.80 \pm 0.76,7.60 \pm 0.92$, and 7.20 \pm 0.92 respectively in group I, group II, and group III. While at $2^{\text {nd }}, 4^{\text {th }}$ and $6^{\text {th }}$ day there was statistical significance decrease in mean size of the ulcer in group I $(5.70 \pm 0.42,3.80 \pm 0.38,3.10 \pm 0.34)$ when compared to group III $(4.10 \pm 0.46,2.70 \pm 0.29$, $2.10 \pm 0.21)$ respectively $\mathrm{P}<0.01$. Also, there was non-statistical significance decrease in mean size of the ulcer between group II when compared with group III at all evaluation periods (table 1, Fig. 4).

Kuruskal-wallis test showed statistical significance increase in mean percentage reduction of ulcer size in (group III) when compared to (group I) at all evaluation periods. In addition, there was statistical significance increase in mean percentage reduction of ulcer size at $2^{\text {nd }}, 4^{\text {th }}$ and $6^{\text {th }}$ day in group I $(26.92 \pm 3.7,51.28 \pm 4.8,60.26 \pm 3.2)$ when compared to group II $(40.79 \pm 1.59,63.16 \pm 0.18$, $71.05 \pm 2.17$ ) respectively $\mathrm{P}<0.01$ respectively. On the other hand, there was non-statistical significance difference in mean percentage reduction of ulcer size between (group II) when compared with (group III) at all evaluation periods (table 1, Fig.5).

\section{Pain score}

Wong-Baker faces pain rating scale (Fig. 3) was used to access non-contact pain during all evaluation periods $0,2^{\text {nd }}, 4^{\text {th }}$ and $6^{\text {th }}$ day. At day (0) there was non-statistical significant difference in the mean of pain score between the three treated groups; it was $6.00 \pm 0.35,5.80 \pm 0.37$, and 5.60 \pm 0.92 respectively in group I, group II, and group III. On the other hands, at $2^{\text {nd }}, 4^{\text {th }}$ and $6^{\text {th }}$ day there was statistical significant decrease in the mean of pain score of group I $(4.61 \pm 0.28,3.80 \pm 0.25,2.78$ $\pm 0.15)$ when compared to group III $(2.73 \pm 0.19$, $2.11 \pm 0.16,1.00 \pm 0.11$ ) respectively $\mathrm{P}<0.01$. Also, there was statistical significant decrease in the mean

TABLE (1) Mean \pm standard deviation (SD) value of aphthous ulcers size and percentage reduction in size at all evaluation periods in the different treated groups.

\begin{tabular}{|c|c|c|c|c|}
\hline Time of evaluation & Hyaluronic acid & Laser & Laser/ Hyaluronic acid & P-value \\
\hline Day 0 & $7.80 \pm 0.76$ & $7.60 \pm 0.92$ & $7.20 \pm 0.92$ & 0.5570 \\
\hline Day 2 & $5.70 \pm 0.42^{\mathrm{a}}$ & $4.50 \pm 0.48^{\mathrm{b}}$ & $4.10 \pm 0.46^{\mathrm{c}}$ & $<0.001^{* *}$ \\
\hline Day 4 & $3.80 \pm 0.38^{\mathrm{a}}$ & $2.80 \pm 0.31^{\mathrm{b}}$ & $2.70 \pm 0.29^{\mathrm{b}}$ & $<0.001^{* *}$ \\
\hline Day 6 & $3.10 \pm 0.34^{\mathrm{a}}$ & $2.20 \pm 0.19^{\mathrm{b}}$ & $2.10 \pm 0.21^{\mathrm{b}}$ & $<0.001^{* *}$ \\
\hline \% reduction of size in day 2 & $26.92 \pm 3.73^{\mathrm{b}}$ & $40.79 \pm 1.59^{\mathrm{a}}$ & $43.06 \pm 1.26^{\mathrm{a}}$ & $0.004^{* *}$ \\
\hline \% reduction of size in day 4 & $51.28 \pm 4.82^{\mathrm{b}}$ & $63.16 \pm 0.1 .86^{\mathrm{a}}$ & $62.50 \pm 2.01^{\mathrm{a}}$ & $0.018^{* *}$ \\
\hline \% reduction of size in day 6 & $60.26 \pm 3.20^{\mathrm{b}}$ & $71.05 \pm 2.17^{\mathrm{a}}$ & $70.83 \pm 3.52^{\mathrm{a}}$ & $0.005^{* *}$ \\
\hline
\end{tabular}

** means that different superscripts in the same row are statistically significantly different between groups using KruskalWallis test at $P$ value $\leq 0.01 \quad$ Data expressed as mediand range *: significance $\leq 0.01$

Small letters indicate significance between time (a: significance vs Baseline; $b$ : significance vs 2 days; c: significance vs 4 days) 
of pain score of group I when compared to group II at evaluation periods. On the other Hand, there was non-statistical significant difference in mean of pain score between group II and group III at all evaluation periods (table 2, Fig. 6).

The mean percentage reduction of pain score recorded that, there were statistical significance increase in the mean percentage reduction of pain score at $2^{\text {nd }}, 4^{\text {th }}$ and $6^{\text {th }}$ day in group I $(23.17 \pm$

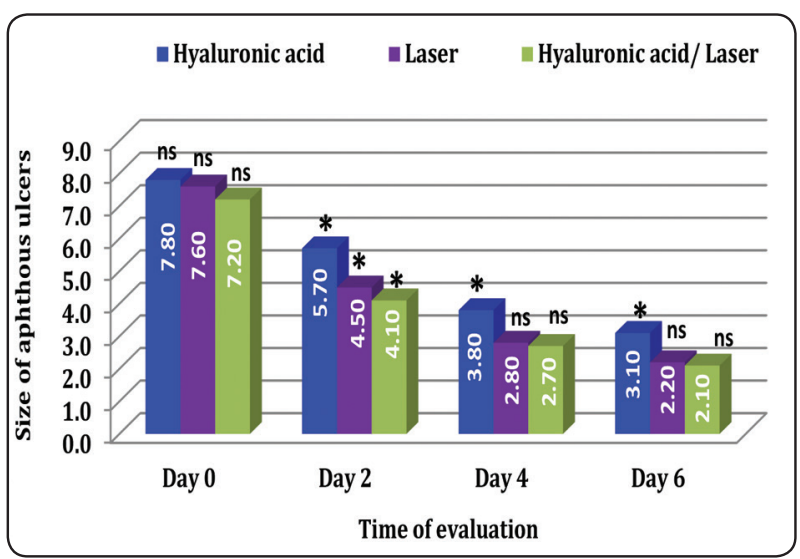

Fig. (4) Mean size of aphthous ulcers at different evaluation periods with different treatment modalities, ns means statistically non-significant different, * mean statistically significantly different
$2.3,36.6 \pm 3.04,53.67 \pm 2.42)$ when compared with group III $(51.25 \pm 4.73,62.32 \pm 4.37,82.14$ \pm 2.26 ) respectively $\mathrm{P}<0.01$. There was statistical significance increase in mean percentage reduction of pain score of group I when compared with group II at all evaluation periods $\mathrm{P}<0.01$. On the other hand, there was non-statistical significance difference in mean percentage reduction of pain score between (group II) when compared with (group III) at all evaluation periods (table 2, Fig. 7).

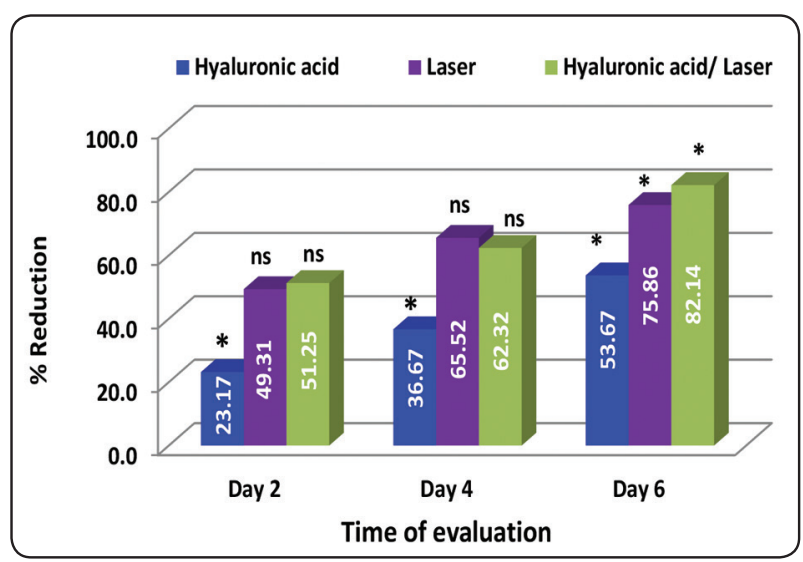

Fig. (5) Mean percentage reduction of size of aphthous ulcers at different evaluation periods with different treatment modalities, ns means statistically non-significant different, * mean statistically significantly different

TABLE (2) Mean \pm standard deviation (SD) value of pain level and percentage reduction in pain at all evaluation periods in the different treated groups.

\begin{tabular}{|c|c|c|c|c|}
\hline Time of evaluation & Hyaluronic acid & Laser & Laser/ Hyaluronic acid & P-value \\
\hline Day 0 & $6.00 \pm 0.35$ & $5.80 \pm 0.37$ & $5.60 \pm 0.29$ & $\mathbf{0 . 3 5 4}$ \\
\hline Day 2 & $4.61 \pm 0.28^{\mathrm{a}}$ & $2.94 \pm 0.19^{\mathrm{b}}$ & $2.73 \pm 0.19^{\mathrm{c}}$ & $<\mathbf{0 . 0 0 1} * *$ \\
\hline Day 4 & $3.80 \pm 0.25^{\mathrm{a}}$ & $2.00 \pm 0.20^{\mathrm{b}}$ & $2.11 \pm 0.16^{\mathrm{b}}$ & $<\mathbf{0 . 0 0 1} * *$ \\
\hline Day 6 & $2.78 \pm 0.15^{\mathrm{a}}$ & $1.40 \pm 0.11^{\mathrm{b}}$ & $1.00 \pm 0.11^{\mathrm{b}}$ & $<\mathbf{0 . 0 0 1 * *}$ \\
\hline \% reduction of pain in day $\mathbf{2}$ & $23.17 \pm 2.30^{\mathrm{b}}$ & $49.31 \pm 3.92^{\mathrm{a}}$ & $51.25 \pm 4.73^{\mathrm{a}}$ & $<\mathbf{0 . 0 0 1 * *}$ \\
\hline \% reduction of pain in day 4 & $36.67 \pm 3.04^{\mathrm{b}}$ & $65.52 \pm 4.62^{\mathrm{a}}$ & $62.32 \pm 4.37^{\mathrm{a}}$ & $<\mathbf{0 . 0 0 1} * *$ \\
\hline \% reduction of pain in day 6 & $53.67 \pm 2.42^{\mathrm{c}}$ & $75.86 \pm 3.12^{\mathrm{a}}$ & $82.14 \pm 2.26^{\mathrm{a}}$ & $<\mathbf{0 . 0 0 1} * *$ \\
\hline
\end{tabular}

** means that different superscripts in the same row are statistically significantly different between groups using KruskalWallis test at $P$ value $\leq 0.01$

Data expressed as median\& range *: significance $<0.05$

Small letters indicate significance between time (a: significance vs Baseline; b: significance vs 2 days; : significance vs 4 days) 


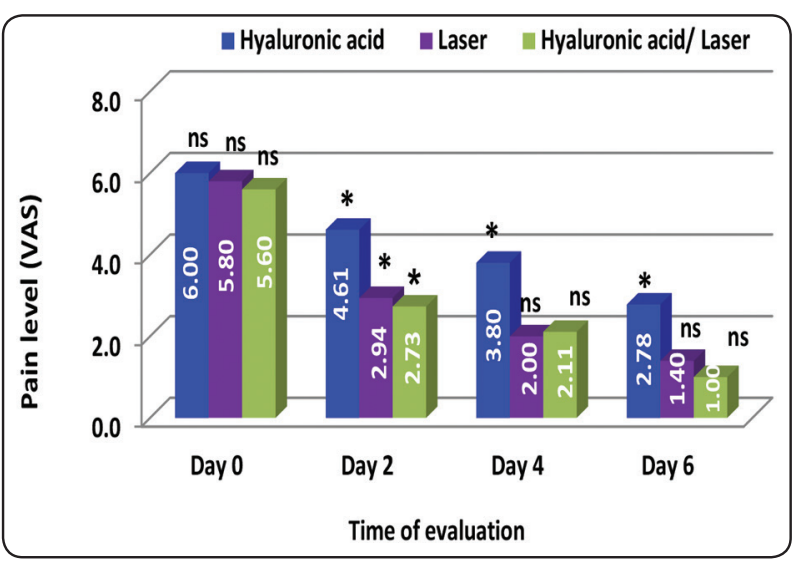

Fig. (6) Mean pain score at different evaluation periods with different treatment modalities, ns means statistically non-significant different, * mean statistically significantly different

\section{DISCUSSION}

RAS has multifactorial etiology and it lacks effective treatment. RAS is painful ulcers bring about trouble in eating, swallowing, and speaking. The aim of the management was to decline pain, curing time and size of the ulcer ${ }^{(21)}$.

In this study, local treatments were used to avoid the bad effects of systemic drugs, this agrees with Puratchikody et al ${ }^{(22)}$ who decided that local drug carriage systems have been commonly developed for treatment of oral lesions.

Children participated in this study because of high prevalence of aphthous ulcer between them, it is reported to affect up to $40 \%$ of children, episodes of aphthus ulcer in child have been shown to have a significant impact negatively on quality of life of a child, interfering with eating, speaking and may result in missed school days. Male and female children aged from 4-10 years with average age 4 \pm 6.8 included in our study was based on the study of porter et al, 1998 who reported that there was an equal ratio of prevalence of RAS until age of 10 years ${ }^{(1,2,23)}$

In the current study a comparison between the effects of diode laser, hyaluronic acid gel, and diode

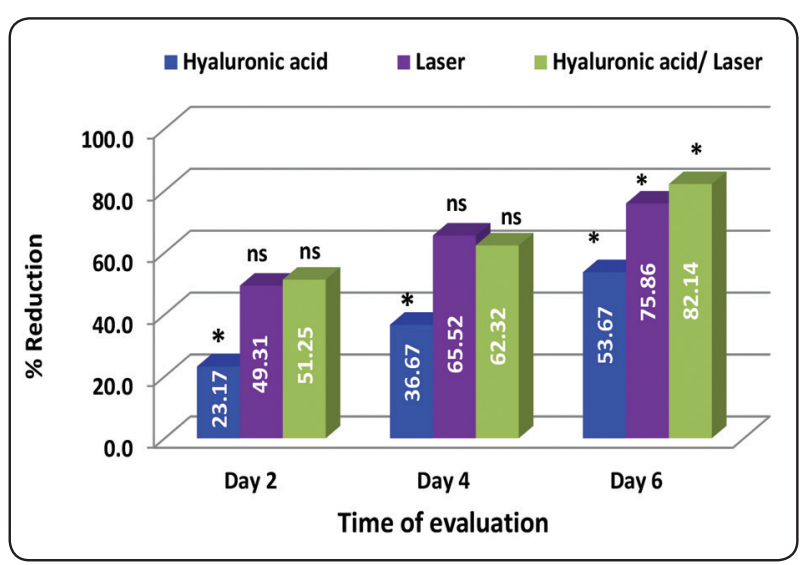

Fig. (7) Mean \% reduction of pain at different evaluation periods with different treatment modalities, ns means statistically non-significant different, * mean statistically significantly different

laser combined with hyaluronic acid gel in the management of RAS was performed. Using topical application of $0.2 \% \mathrm{HA}$ gel in this research was based on the study of Lee et al. who concluded that topical application of $0.2 \% \mathrm{HA}$ gel is effective and harmless therapy in patients with RAS ${ }^{(24)}$. On other hand, Lalabonova et al. concluded that using lowlevel laser therapy (LLLT) in management of RAS was better than group treated with pharmacotherapy. Moreover, Pain and inflammation decreased with LLLT. Healing has been also significantly enhanced (25).

In this study, measuring reduction of pain and evaluation of lesion size were used for evaluation of different treatment modalities of RAS. This is in agreement with Sherine et al., who evaluated the effects of Amlexanox oral paste and low level laser therapy on treatment of RAS by evaluation of pain reduction and measurement of ulcer sizes ${ }^{(18)}$.

Wong-Baker faces scale (1: 6) was used to evaluate pain during different periods of evaluation in this study; this scale was selected for easy performance of children above 3 years. On other hands visual analoge scale was used in pain evaluation in many studies ${ }^{(26-28)}$. Also, Dalessandri et al., assessed pain of RAS by using 4- level pain scale ${ }^{(29)}$. 
The frequency of recurrence of ulcers was not inspected in this study; this is because no study proved any reduction in the recurrence rate of aphthous ulcers ${ }^{(30)}$. In addition, this study did not perform routine laboratory procedures because it was not essential. History of ulcer include (duration, shape, size and site) was the basic distinguishing of $\operatorname{RAS}^{(31)}$.

HA used in this study for management of RAS was in accordance with Nolan et al., who stated that HA $0.5 \%$ is responsible for quickly decline in pain after application nevertheless of the stage of ulceration. In addition, it can be used in infants and pregnant women without any undesirable effects or drug interactions ${ }^{(19)}$.

In the present study topical HA was used for management of RAS in accordance with Casale et al., who stated that HA was benefit in management of gingival and periodontal diseases, as well as during the postoperative period of various surgical procedures. It was effective in early curing and diminishing patient's distress during the postoperative period ${ }^{(18)}$. In addition, this agrees with Nolan et al., who concluded that Topical applications of HA $0.2 \%$ has many advantage in the management of RAS ${ }^{(19)}$. Immediate use decreased discomfort and obstructed any stimuli ascending from the oral environment. HA $0.2 \%$ promoted healing of RAS as it decreased ulcer duration and rate of recurrences when patients were treated with it ${ }^{(32)}$.

In addition, Nolan et al., inspected the different effects of HA in patients with recurrent oral ulcers; they proved that HA gel significantly decreased the number of ulcers, healing period and pain. These results suggest that HA may act as a wall, that protects any ulcers from painful stimuli. Moreover, the inflammatory signs were significantly deceased ${ }^{(19)}$.

The results of this study in group I recorded decrease in mean of ulcer size and pain score this may be due to adjusting tissue hydration in the periods of inflammation process. This improves cell proliferation and migration ${ }^{(19)}$. This results in the decreasing of cell anchorage to the extra cellular matrix that permitting short-term detachment to assist cell migration and division ${ }^{(33)}$. In the hydrated state, much of the water around the HA molecule is arrested which results in limitation of movement of water and small molecules ${ }^{(34)}$. Moreover, HA is viscous which decreases secondary infection by viral and bacterial attack through the HA-rich pericellular zone ${ }^{(35,36)}$. In inflammation, HA may also have a moderate effect through free-radical scavenging, antioxidant effect, and exclusion of tissue degrading enzyme. Moreover, the reduction in pain sensation in HA treated group may be attributed to reduction of the painful stimulatory inflammatory mediators that released by mast cells to the nerve ending in inflammatory phase. ${ }^{(37)}$

Selecting diode laser in this work was due to the many advantageous of this type over high powered laser in treatment of soft tissue lesions. it does not cause thermal injury to the tissues, inexpensive, easy to use, with greater electrical and optical efficiencies ${ }^{(38)}$. Less than one $\mathrm{W}(0.4 \mathrm{w})$ was used in this study, because all tissues reactions in aphthous ulcerations occur in the epithelium so use of high power laser treatment not indicated in treatment of this ulcer ${ }^{(39)}$. A continuous mode of application was used in current study, this disagree with De Souzaet al., who used A refractory period of 1520 seconds in laser application mode for cooling down the tissues ${ }^{(40)}$. Also they revealed decrease in pain in the same session after laser application and regression in lesion size after 4 days in comparison to corticosteroid therapy that decreased pain after 5-7 days.

In addition the results of the present study proposed that in diode laser (group II) increase percentage reduction of ulcer size that may be occurred due to encouraging collagen fabrication, changing DNA synthesis and improving the function of neurological tissue in accordance with Anand et al., who found this in two case reports using LLLT in lowering pain and ulcer size ${ }^{(38)}$. 
In our present study, diode laser provided decrease in mean of pain score during all evaluation periods which may be attributed to the fact that LLLT motivates the fabrication of $\beta$-endorphins which causing pain relief. It has an intense effect on $\mathrm{C}$ fibers leading to a reduced action of these fibers and changing the pain threshold ${ }^{(41)}$. Also Agarrwal et al. revealed that the usage of LLLT prevents the transmission of pain to nerve fibers. They suggested that change in pain threshold may be due to alteration the voltage-gated $\mathrm{Na}-\mathrm{K}$ channels that is similar to the action of local anesthetic agents..$^{[22]}$

These results from group II in agreement with the study of Bladowski et al. ${ }^{[43]}$ who explained the possible mechanisms of LLLT in increasing ATP synthesis that lead to an improvement in mitotic activity with rise in protein formation by mitochondria, resulting in greater tissue regeneration in the repair. ${ }^{[42]}$ In addition provides a incitement to microcirculation, which increases rate of mitosis, leading to neoangiogenesis. ${ }^{[41]}$

The results of the current study revealed that the group treated with diode laser combined with hyaluronic acid gel has highly percentage reduction in the mean of both ulcer size and pain score during all evaluation periods. This may be attributed to the anti- inflammatory and biostimulatory effects with increased tissue vascularity and capillary vasodilation of firstly used diode laser and so lead to easy, more rapid absorption, and more effectiveness of the secondary topically applied hyaluronic acid gel.

\section{CONCLUSION}

The present study concluded that hyaluronic acid gel easy applicable, non-toxic and well tolerated for children. It promotes healing for RAS. Hyaluronic acid gel and diode laser reduce size and pain so, they are effective in treatment of RAS. Diode laser reduce RAS pain immediately and its time benefit. Use diode laser followed by topical application of hyaluronic acid gel lead to high percentage reduction of pain and ulcer size, without any side effect and complain during treatment.

\section{RECOMMENDATIONS}

This study recommended further studies with longer evaluation period, large number of patient needed to evaluate frequency of recurrence of aphthous ulcer in children after the three different treatment modalities. Further studies in cellular bases needed to understand the mechanisms of healing with different treatment modalities.

Limitations of the present study include Difficuly in selection of children with RAS with our inclusion criteria. Short evaluation periods so, future studies with longer evaluation period is needed.

\section{REFERENCES}

1. Chavan M, Jain H, Diwan N, Khedkar S, Shete A, Durkar S. Recurrent aphthous stomatitis: a review. J Oral Pathol Med. 2012;41:577-83.

2. Parter SR, Scully C, Pedersen A. Recurrent aphthous stomatitis. Crit Rev Oral Biol Med. 1998;9:306-21.

3. Pongissawaranun W, Laohapand P. Epidemiological study on recurrent aphthous stomatitis in a Thai dental population. Community Dent Oral Epidemiol. 1991;19:52-3.

4. Thakrar P, Chaudhry SI. Oral mucosal ulceration: an overview of diagnosis and management. Prim Dent J. 2016;46:5:30-3.

5. Woo SB, Sonis ST. Recurrent aphthous ulcer: a review of diagnosis and treatment. J Am Dent Assoc. 1996; $127: 1202-13$

6. Femanio f, lanz a, Buonaiuto a, et al. Guidelines for diagnosis and management of aphthous stomatitis. Pediatr Infect Dis J. 2007;26(8):728-32.

7. Wallace A, rogers HJ, hughes SC, et al. Management of recurrent aphthous stomatitis in children. Oral Medicine. 2015;42(6):564-72.

8. Cawson RA, Odell EW. Essentials of oral pathology and oral medicine, sixth edition, Churchill Livingstone, London; 1998.183- 6

9. Glick M, William M. Burket's Oral Medicine. 12th ed. People's Medical Publishing House: USA; 2015. P.104-8.

10. Necas J, Bartosikova L, Brauner P, Kolar J. Hyaluronic acid (hyaluronan): a review. Veterinarni Medicina 2008; 53:397-411. 
11. Sasaki T, Watanabe C. Stimulation of osteoinduction in bone wound healing by high-molecular hyaluronic acid. Bone.1995;16:9-15.

12. Peattle RA, Nayate AP, Firpo MA, Shelby J, Fisher RJ, Prestwich GD. Stimulation of in vivo angiogenesis by cytokine loaded hyaluronic acid hydrogel implants. Biomaterials 2004;25:2789- 98.

13. Neuman MG, Nanau RM, Oruna-Sanchez L, Coto G. Hyaluronic acid and wound healing. J Pharm Pharm Sci, 2015; 18:53-60.

14. Engstrom PE, Shi XQ, Tronje G, Larsson A, Welander U, Frithiof L, Engstrom GN .(2001) The effect of hyaluronan on bone and soft tissue and immune response in wound healing. J Periodontol . 2001; 72: 1192- 1200.

15. Pirnazar P, Wolinsky L, Nachnani S, Haake S, Pilloni A, Bernard GW. Bacteriostatic effects of hyaluronic acid. J Periodontol . 1999; 70:370-374.

16. Nasim Zeini Jahromi , Janan Ghapanchi, Sara Pourshahidi, Maryam Zahed, Hooman Ebrahimi. Clinical Evaluation of High and Low-Level Laser Treatment (CO2 vs InGaAlP Diode Laser) for Recurrent Aphthous Stomatitis. J Dent Shiraz Univ Med Sci., 2017 March; 18(1): 17-23.

17. Sherine A. Nasry, Hanaa M. El Shenawy, Dina Mostafa, Nagwa M. Ammar. Different modalities for treatment of recurrent aphthous stomatitis. A Randomized clinical trial. J Clin Exp Dent. 2016;8(5):e517-22.

18. Nolan A, Baillie C, Badminton J, Rudralingham M, Seymour R. The efficacy of topical hyaluronic acid in the management of recurrent aphthous ulceration. J Oral Pathol Med 2006; 35: 461-5.

19. Wong-Baker FACES Rating Scale: From Wong DL, Hackenberry-Eaton M, Wilson D, Winkelstein ML, Schwartz P: Wong's Essentials of Pediatric Nursing, 6/e, St. Louis, 2001, P. 1301. Copyrighted by Mosby, Inc. Reprinted with permission.

20. Baccaglini L, Lalla RV, Bruce AJ, Sartori-Valinotti JC, Latortue MC, Carrozzo M. Urban legends:recurrent aphthous stomatitis. Oral Dis. 2011;17:755-70.

21. Puratchikody A, Prasanth VV, Mathew ST, Kumar BA. Development and characterization of mucoadhesive patches of salbutamol sulfate for unidirectional buccal drug delivery. Acta Pharm. 2011;61:157-70.

22. Montgomery-Cranny JA, Wallace A, Rogers HJ, Hughes SC, Hegarty AM, Zaitoun H. Management of Recurrent
Aphthous Stomatitis in Children. Dent Update. 2015 JulAug; 42(6):564-6, 569-72.

23. Lee JH, Jung JY, Bang D. The efficacy of topical $0.2 \%$ hyaluronic acid gel on recurrent oral ulcers: comparison between recurrent aphthous ulcers and the oral ulcers of Behçet's disease. J Eur Acad Dermatol Venereol. 2008;22:590-5.

24. Lalabonova H, Daskalov H. Clinical assessment of the therapeutic effect of low-level laser therapy on chronic recurrent aphthous stomatitis. Biotechnol Biotechnol Equip. 2014;28:929-33.

25. Nasry Sh., El Shenawy H., Mostafa D., Ammar N. Different modalities for treatment of recurrent aphthous stomatitis. A Randomized clinical trial. J Clin Exp Dent. 2016;8(5):e517-22.

26. Farid Abbasi 1, Maryam Raoof 2, Roya Khatami 3, Niloofar Shadman 4, Farnaz Borjian-Boroojeni 5, Farahnaz Nazari 6. Effectiveness of Amlexanox and Adcortyl for the treatment of recurrent aphthous ulcers. J Clin Exp Dent. 2016;8(4):e368-72.

27. Duygu Ofluoglu 1, Sertan Ergun 2 Saman Warnakulasuriya 3, Filiz Namdar-Pekiner 4, Hakkı Tanyeri. An evaluation of the efficacy of a topical gel with Triester Glycerol Oxide (TGO)in the treatment of minor recurrent aphthous stomatitis in a Turkish cohort:A randomized, double-blind, placebo-controlled clinical trial Med Oral Patol Oral Cir Bucal. 2017 Mar 1;22 (2):e159-66.

28. Dalessandri D, Zotti F, Laffranchi L, Migliorati M, Isola G, Bonetti S, Visconti L. Treatment of recurrent aphthous stomatitis (RAS; aphthae; canker sores) with a barrier forming mouth rinse or topical gel formulation containing hyaluronic acid :a retrospective clinical study.BMC Oral Health . $2019 ; 19: 1-10$.

29. Jurge S, Kuffer R, Scully C, Porter SR. Mucosal disease series. Number VI. Recurrent aphthous stomatitis. Oral Dis. 2006;12:1-21.

30. Natah SS, Konttinen YT, Enattah NS, Ashammakhi N, Sharkey KA, Häyrinen-Immonen R. Recurrent aphthous ulcers today: a review of the growing knowledge. Int $\mathrm{J}$ Oral Maxillofac Surg. 2004;33:221-34.

31. Casale M, Moffa A, Vella P, Sabatino L, Capuano F, Salvinelli B, Lopez M, Carinci F and Salvinelli F. Hyaluronic acid: Perspectives in dentistry. A systematic review International Journal of Immunopathology and Pharmacology. 2016; Vol. 29(4) 572-82. 
32. Culp LA, Murray BA, Rollins BJ. Fibronectin and proteoglycans as determinants cell-substratum adhesion. J Supramol Struct 1979; 11: 401-27.

33. Ogston AG, Sherman TF. Effects of hyaluronic acid upon diffusion of solutes and flow of solvent. J Physiol 1961; 17: $1-8$.

34. Clarris BJ, Fraser JR. On the pericellular zone of some mammalian cells in vitro. Exp Cell Res 1968; 49: 181-93.

35. Kvam BJ, Fragonas E, Degrass A, et al. Oxygen-derived free radical (ODFR) action on hyaluronan (HA), on two HA ester derivatives, and on the metabolism of articular chondrocytes. Exp Cell Res 1995; 218: 79-86.

36. Cortivo R, Brun P, Cardarelli L, et al. Antioxidant effects of hyaluronan and its alpha-methyl-prednisolone derivative in chondrocyte and cartilage cultures. Semin Arthritis Rheum 1996; 26: 492-501.

37. Anand V, Gulati M, Govila V, Anand B. Low level laser therapy in the treatment of aphthous ulcer. Indian J Dent Res. 2013;24: 267-70.
38. Sattayut S, Trivibulwanich J, Pipithirunkarn N, Danvirutai N. A clinical efficacy of using $\mathrm{CO} 2$ laser irradiating to transparent gel on aphthous stomatitis patients. Laser Ther. 2013;22: 283-9.

39. De Souza TO, Martins MA, Bussadori SK, Fernandes KP, Tanji EY, Mesquita-Ferrari RA, et al. Clinical evaluation of low-level laser treatment for recurring aphthous stomatitis. Photomed Laser Surg. 2010;28:S85-8

40. Butchi B, Uday K, Bassel T, Khaja A, Saleh N, Ibrahim A. Versatility of diode lasers in low-level laser therapy for the management of recurrent aphthous stomatitis. Journal of Orofacial Sciences . 2015;49 Vol. 7. Issue 1. January.

41. Aggarwal H, Singh MP, Nahar P, Mathur H, Gv S. Efficacy of low level laser therapy in treatment of recurrent aphthous ulcers: A sham controlled, split mouth follow up study. J Clin Diagn Res 2014;8:218-21.

42. Bladowski M, Choroszucha HK, Choroszucha T. Comparison of treatment results of recurrent aphthous stomatitis with low and high power laser irradiation versus pharmaceutical method. J Oral Laser Appl 2004;4:191-209. 